\title{
Seasonal changes in size, sex-ratio and body condition of the damselfish Chromis chromis in the central Mediterranean Sea
}

\author{
CLAUDIA BRACCIALI ${ }^{1,2}$, SUSANNA PIOVANO ${ }^{1,3}$, GIANLUCA SARA ${ }^{2}$ AND CRISTINA GIACOMA ${ }^{1}$ \\ ${ }^{1}$ Department of Life Sciences and Systems Biology, University of Torino, Via Accademia Albertina 13, 10123 Torino, Italy, \\ ${ }^{2}$ Dipartimento di Scienze della Terra e del Mare, Università di Palermo, Viale delle Scienze Ed. 16, 90128 Palermo, Italy, ${ }^{3}$ Current address: \\ School of Biological and Chemical Sciences, The University of the South Pacific, Laucala Campus, Private Mail Bag, Suva, Fiji
}

\begin{abstract}
Chromis chromis is one of the most abundant fish species on the Mediterranean rocky shores. Acting as a by-pass of nutrients from the pelagic to the rocky littoral system, it plays an important role as a resource provider and has a relevant function in the community assemblage. Chromis chromis has many of the characteristics required of an indicator species (e.g. it is easy to recognize in the field, small sized, widespread and abundant). In this study we focused on individual size, sex-ratio and body condition in a damselfish population occurring in a central Mediterranean marine protected area. Fishing trials on a monthly basis (April-November) allowed us to assess seasonal changes in population structure. Fish were measured and weighed and a subsample was aged and sexed. On average, males were larger than females. The allometric coefficient, $\mathrm{b}$, for the whole population was 2.99; the maximum age recorded was $7.5 \mathrm{yr}$. Before reproduction sex-ratio was close to parity (M:F 1:0.78), while a larger proportion of females was captured during the reproductive period. In conclusion, our results show that the population dynamics of $\mathrm{C}$. chromis is influenced by both sex and size. Since males and females have different behavioural strategies, and since the length of the spawning period is shorter in the smaller than in the larger-sized individuals, this is reflected in temporal changes observed in the population structure.
\end{abstract}

Keywords: damselfish, seasonal changes, body size, body condition, sex-ratio, Mediterranean Sea

Submitted 25 September 2013; accepted 5 March 2014; first published online 24 April 2014

\section{INTRDDUCTION}

The damselfish Chromis chromis is one of the most abundant fish of Mediterranean rocky littorals (Guidetti, 2000). It is a widespread species along the coasts of the Mediterranean, the Black Sea and the eastern Atlantic areas next to the Mediterranean (Allen, 1991). Despite being generally of no commercial importance, it is offered on the markets of some Mediterranean countries (e.g. Cyprus and Morocco: Fischer et al., 1987; Croatia: Grubišić, 1982, cited in Dulčić \& Kraljević, 1995; Dulčić et al., 1994). Elsewhere it is a bycatch fish and is discarded from the purse seine fisheries targeting small pelagic fish in the eastern Mediterranean (Tsagarakis et al., 2012), as well as from trammel nets in the Aegean (Gonçalves et al., 2007).

Due to its abundance in the rocky littoral system (it accounts for more than $50 \%$ of all observed individuals in some sites; Fasola et al., 1996) and its relevant function in community assemblage (Pinnegar \& Polunin, 2006), C. chromis may be described as a foundation stone species (Jones et al., 1994). It plays an important role as a resource cycler and provider by transferring nutrients such as nitrogen and phosphates from the water column, where it feeds on zooplankton, to the rocky littoral system,

Corresponding author:

C. Bracciali

Email: claudiabracciali@gmail.com where it rests and excretes its wastes (Pinnegar \& Polunin, 2006). Considering the oligotrophy of Mediterranean waters, some authors have suggested that the nutrient enrichment due to compounds excreted by $C$. chromis may enhance littoral primary productivity (Pinnegar et al., 2007).

Moreover, the damselfish has many of the characteristics of an indicator species: it is small sized, abundant and easily recognized in the field; it is not a fishing target and is not migratory (Linton \& Warner, 2003). Also Guidetti \& Sala (2007) observed significant differences in C. chromis abundance between Mediterranean marine reserves and fishing areas. Damselfish is also among the species that aggregate in Sparus auratus and Thunnus thynnus farms and whose distribution may accordingly be affected by farming activities (Bacher et al., 2012). In addition, significant effects of boat noise on $C$. chromis behaviour have been reported by Picciulin et al. (2010) and by Bracciali et al. (2012).

Gaining a better understanding of the population structure of such an abundant and ecologically relevant species, as well as of fluctuations occurring in its life parameters throughout the year, may be very useful to ensure the early detection of cryptic environmental changes in parameters such as food availability and perhaps water temperature, as well as for devising better conservation and management practices in coastal areas. In this study we focused on individual size, sex-ratio and body condition.

Larger individuals usually perform better in competition for resources such as food, refuges and breeding sites 
(Webster \& Hixon, 2000; Hobbs \& Munday, 2004; Fero \& Moore, 2008). In spite of the costs involved in defending their high rank within the group, they are able to store more energy reserves to be allocated in maintenance, growth and reproduction (Pecquerie et al., 2009). On the other hand, when food uptake is insufficient to support all metabolic processes, energetic reserves can be mobilized from the reproductive buffer (Kooijman, 2010; Sarà et al., 2014). Multiple-batch spawning species, such as damselfish (family Pomacentridae), are able to adapt the number of spawning cycles at the individual level and can temporarily suspend oocyte maturation when food supply is limited (Bapary et al., 2012).

Body size also has an influence in the mating strategy adopted. Larger males are more likely to acquire territories and mates (reviewed in Endler, 1986; Andersson, 1994; Blanckenhorn, 2005). Smaller individuals may adopt a different behaviour. In species with alternative or conditional strategies, the ability of smaller males to behave differently yields a higher pay-off than if such individuals try to adopt the same behaviour as bigger individuals (Gross, 1996). Consequently, the amount of time spent in reproductive activity may be rather variable among individuals within the same population, not only as a function of abiotic variables such as light and the temperature, but also depending on individual size and food availability (Donelson et al., 2010; Armstrong \& Witthames, 2012).

All damselfish share a similar reproductive behaviour (Froese \& Pauly, 2013). During the spawning period, males leave their feeding habitat, the water column, and move to the sea bottom, where they establish territories, prepare a nest and court females (Hoelzer, 1990; Pankhurst, 1995 Verginella et al., 1999). Females leave the nest immediately after oviposition, while males remain to defend and ventilate the eggs, thereby greatly reducing their feeding activity (Gladstone, 2007a)

Since investing energy in parental care is advantageous for males only when it increases their reproductive success by affording a higher number of hatched eggs (Gladstone, $2007 \mathrm{~b}$ ), when the number of eggs within a nest is low, or when no female lays her eggs in a nest, males may adopt alternative brooding strategies (Taborsky, 1998, 2001). In this framework, the evaluation of the number of males feeding in the water column may be taken as an instrument to assess the length and the intensity of reproductive activity.

The body condition index (BCI) is a morphometric index describing the relationship between body mass and length. When the spawning period is taken into consideration, a decrease in BCI is usually noted, concomitantly with an increase in the mass of gonads (Domínguez-Petit et al., 2010). In the specific case of $C$. chromis, a reduction in BCI can be due to a high investment in gametes in females as well as, for males, to the interruption in feeding, starting with their migration to the bottom and then the energetic investment in nest defence and parental care.

The aim of the present study was to provide baseline data on the population structure and seasonal dynamics of $C$. chromis in the Mediterranean Sea. For this reason, we chose a population living in a marine protected area and assessed seasonal changes in the monthly trends of the male:female ratio in the water column, together with variations in individuals' size and body condition.

\section{MATERIALS AND METHODS}

\section{Study area and sampling}

The present study was run within the marine protected area of 'Capo Gallo e Isola delle Femmine' (hereafter MPA), in the Tyrrhenian Sea (central Mediterranean $38^{\circ} 12^{\prime} 49^{\prime \prime} \mathrm{N}$ $\left.13^{\circ} 16^{\prime} 32^{\prime \prime} \mathrm{E}\right)$. The MPA extends over 2713 ha, has a mean depth of about $15 \mathrm{~m}$ and a vegetated rocky substrate alternating with beds of Posidonia seagrass (see: www.ampcapogallo-isola. org). Chemical and physical parameters were constant within the MPA, and we did not find any difference in density between schools (Bracciali et al., 2012).

Fishing trials were carried out in the morning, between 10.00 and 12.00 hours, on a monthly basis, from April to November 2008. They were performed from a small fishing boat (hull length $10 \mathrm{~m})$ using a seine net $(50 \times 6 \mathrm{~m})$ adapted to the target species. Chromis chromis specimens were frozen and stored at the Laboratory of Experimental Ecology of the University of Palermo. Both commercial and recreational fishing are forbidden in the study area. Only scientific surveys are allowed, subject to a previous authorization by the MPA and by the coastguard.

\section{Data collection}

For each specimen we measured the standard length (SL) to the nearest $0.1 \mathrm{~mm}$ with a Vernier calliper and weight (total wet weight: TW) to the nearest $0.1 \mathrm{~g}$ with a laboratory balance. Specimens were grouped in length-classes of $10.0 \mathrm{~mm}$ each. Accordingly, five SL-classes (SLc) were obtained: A $(<45.0 \mathrm{~mm}) ; \mathrm{B}(45.0-54.9 \mathrm{~mm})$; C (55.0$64.9 \mathrm{~mm})$; D $(65.0-74.9 \mathrm{~mm})$; and $\mathrm{E}(\geq 75.0 \mathrm{~mm})$.

The length-weight relationship was investigated by a standard allometric equation, expressing weight (TW) as a function of length (SL):

$$
T W=a S L^{b}
$$

Age was estimated by reading the annuli on otolith sagitta on a subsample of 1012 specimens ( $11 \%$ of the whole sample). Two operators independently counted the annuli under a stereo microscope (Leica EZ4 D, 12.5 $\times$ magnification). Whenever the older bands were closer to half of a complete annulus, age, expressed in years, was adjusted by adding 0.5 to the count. The final age was the one over which consensus between readers was obtained.

Lengths at discrete ages were used to estimate the growth parameters of our C. chromis population by von Bertalanffy's equation:

$$
L_{t}=L_{\infty}\left(1-e^{-k\left(t-t_{0}\right)}\right)
$$

where $\mathrm{L}_{t}$ is the SL at time $t, \mathrm{~L}_{\infty}$ is the asymptotic average SL $(\mathrm{mm}), k$ is the growth rate $\left(\mathrm{y}^{-1}\right)$ and $t_{\mathrm{o}}$ is the hypothetical age at $\mathrm{L}_{t}=\mathrm{o}(\mathrm{y})$

Sex identification was performed by the macroscopic observation of gonads and was possible only on samples collected from April to August. On average, it was carried out on a monthly subsample of 84 specimens. 
The BCI was calculated as Fulton's $\mathrm{K}$ index (Nash et al., 2006):

$$
B C I=T W / S L^{3}
$$

throughout the whole sample.

\section{Statistical analysis}

Differences in age were tested between the length-classes by one-way ANOVA, according to the SLc (five levels: from SLc A to SLc E), as well as by post-hoc pairwise comparison with Holm's correction.

To evaluate differences between the sex-ratio observed in the first sampling month (April) and the theoretical male:female ratio of 1:1, an exact binomial test was performed. The sex-ratio calculated for each of the months from May to August was then compared to that of the first month of sampling (taken as the expected proportion), by exact binomial test. Since we were interested in evaluating differences between sexes in mature individuals only, immature specimens (SLc A) were excluded from the analysis.

Factorial ANOVAs were performed to analyse the variation of SL and BCI according to sex (two levels: M and F) and month (five levels: from April to August) as orthogonal and fixed factors, as well as to analyse the BCI of the whole sample, according to SLc (four levels: B, C, D and E) and month (eight levels: from April to November), again as orthogonal and fixed factors. Post-hoc pairwise comparisons were run with Holm's correction on within-subject factors. Again, since our interests focused on mature individuals only, immature specimens (SLc A) were excluded from the analysis.

Non-continuous data were transformed into their natural logarithms prior to the ANOVAs. In all tests, significance was set at $\alpha=0.05$. Statistical analyses were performed on R v.3.0.1 (R-Development Core Team, 2013).

\section{RESULTS}

The size of $C$. chromis specimens ranged from 28.1 to $86.6 \mathrm{~mm}$ in length (mean SL $62.8 \mathrm{~mm}$, standard error $(\mathrm{SE})=0.09$ ) and from 0.7 to $25.8 \mathrm{~g}$ in weight (mean $10.4 \mathrm{~g}$, $\mathrm{SE}=0.04)$. The distribution of length frequencies showed a higher percentage of individuals in the central classes (i.e. SLc C and SLc D), which all together represented $78.9 \%$ of the whole sample $(\mathrm{N}=9300)$. The smaller and the larger individuals (e.g. those in SLc A and E) only marginally contributed to the population structure ( $2.5 \%$ and $3.8 \%$, respectively).

Standard length was significantly influenced by sex $\left(\mathrm{F}_{1,411}=18.77, P<0.001\right)$ and by the sampling month $\left(\mathrm{F}_{4,411}=8.80, P<0.001\right)$, but not by the interaction of these factors $\left(\mathrm{F}_{4,411}=2.17, P=0.072\right)$. The mean SL of mature males $(66.5 \mathrm{~mm}, \mathrm{SE}=0.8 \mathrm{o}, \mathrm{N}=165)$ was significantly larger than that of females $(62.3 \mathrm{~mm}, \mathrm{SE}=0.50, \mathrm{~N}=256$; $\mathrm{F}_{1,419}=17.32, P<0.001$ ) (Figure 1).

The overall males:females ratio of mature individuals (SLc $\mathrm{B}-\mathrm{E}, \mathrm{N}=421$ ) was $1: 1.55$, which was significantly different from the expected 1:1 ratio $(P<0.001)$. However, the sexratio fluctuated on a monthly basis, in April showing a proportion of males and females non-significantly different

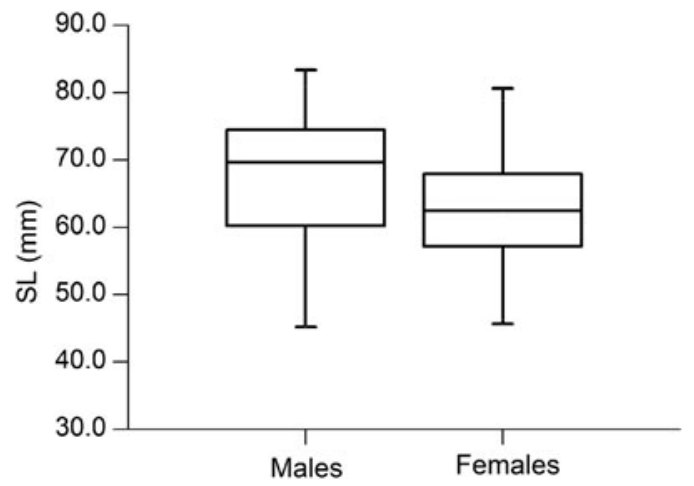

Fig. 1. Distribution of standard length (SL) of mature individuals per sex Each box-plot displays the middle $50 \%$ of SL, the line inside the box shows the median, and lower and upper whiskers represent the minimum and maximum SL values, respectively.

from parity (Table 1) and a larger proportion of females $(65 \%)$ in May-August (Table 1).

For the whole sample, the length - weight relationship was described by the equation in the linearized form:

$$
\log \mathrm{TW}=-4.37+2.98 \times \log \mathrm{SL}
$$

( $R=0.92, \mathrm{~N}=9300, P<0.001)$. The allometric coefficient $b$ was close to the value of 3 which, according to Gould (1966), describes isometric growth.

The relationship between length and age for the whole sample was described by the von Bertalanffy's growth curve shown in Figure 2.

Age was significantly different among the SLc classes $\left(\mathrm{F}_{4,1007}=227.35, P<0.001\right)$, and older individuals were progressively larger (Table 2 ). The oldest individual in our sample was $7.5 \mathrm{yr}$.

For mature individuals, BCI was significantly influenced by month $\left(\mathrm{F}_{4,411}=50.97, P<0.001\right)$ and by the interaction between month and sex $\left(\mathrm{F}_{4,411}=8.30, P<0.001\right)$, but not by sex alone $\left(\mathrm{F}_{1,411}=0.87, P=0.351\right)$.

The BCI changed over months in both males and females, but in a significantly different way $\left(\mathrm{F}_{1,419}=5.90, P=0.016\right)$. In general, BCI decreased from April to August (Figure 3). In males, significant differences were found comparing April with May and June with July $(P<0.001$ and $P=0.030$, respectively, Figure 3 ). In females, the BCI gradually decreased showing a suggestive, but non-significant difference between April and May $(P=0.052)$, while a significantly lower BCI

Table 1. Sex-ratio of Chromis chromis captured monthly from April to August. Sex-ratios from May to August (active reproductive period) were compared to the sex-ratio of April (pre-reproductive period). The latter was compared with an expected 1:1 ratio. $\mathrm{M}$, males; $\mathrm{F}$, females. Significant $P$ values are in bold.

\begin{tabular}{lrr}
\hline Month & M:F & \multicolumn{1}{c}{$\boldsymbol{P}$} \\
\hline April & $1: 0.78$ & 0.295 \\
May & $1: 2.39$ & $<0.001$ \\
June & $1: 1.03$ & 0.087 \\
July & $1: 1.81$ & $<0.001$ \\
August & $1: 3.20$ & $<0.001$ \\
\hline
\end{tabular}




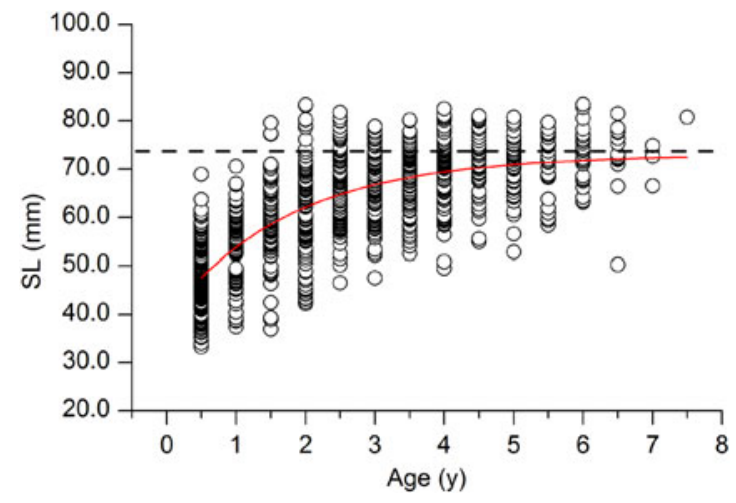

Fig. 2. Von Bertalanffy growth curve. Dashed line represents the asymptotic average length, estimated by the model at $72.9 \mathrm{~mm}$. Other parameter estimates: growth coefficient $k=0.567 \mathrm{y}^{-1}, \mathrm{t}_{\mathrm{o}}=-1.366 \mathrm{y}$.

Table 2. Descriptive statistics of age (mean and standard error (SE)) per SL class (SLc) and $P$ values from post-hoc pairwise comparison with Holm's correction. All $P$ values are significant.

\begin{tabular}{lllllllll}
\hline SLc & mm & $\begin{array}{l}\text { mean } \\
(\mathbf{y})\end{array}$ & SE & $\boldsymbol{P}$ & & & & \\
\hline $\mathrm{A}$ & $<45$ & 0.7 & 0.04 & & $\mathrm{~B}$ & $\mathrm{C}$ & $\mathrm{D}$ & $\mathrm{E}$ \\
$\mathrm{B}$ & $45-54.9$ & 1.1 & 0.07 & $\mathrm{~A}$ & 0.008 & $<0.001$ & $<0.001$ & $<0.001$ \\
$\mathrm{C}$ & $55-64.9$ & 2.3 & 0.07 & $\mathrm{~B}$ & & $<0.001$ & $<0.001$ & $<0.001$ \\
$\mathrm{D}$ & $65-74.9$ & 3.6 & 0.07 & $\mathrm{C}$ & & & $<0.001$ & $<0.001$ \\
$\mathrm{E}$ & $\geq 75$ & 4.1 & 0.14 & $\mathrm{D}$ & & & & 0.002 \\
\hline
\end{tabular}

was found by comparing May with June and June with July $(P<0.001$ in both cases, Figure 3$)$.

For the whole sample, BCI was significantly influenced by month $\left(\mathrm{F}_{7,8821}=78.4, P<0.001\right)$, SLc $\left(\mathrm{F}_{3,8821}=70.4, P<\right.$ $0.001)$ and by their interaction $\left(\mathrm{F}_{21,8821}=5.6, P<0.001\right)$.

The BCI of smaller mature individuals (SLc B) showed a downward trend culminating in a negative peak in July, followed by an upward trend (Figure $4 \mathrm{~A}$ ). In larger specimens (SLc C and D) the negative trend reached its peak one month later (i.e. in August) and was followed by a fluctuation, showing a rise in September, a fall in October and another rise in November (Figure $4 \mathrm{~B}-\mathrm{D}$ ). Specimens belonging to SLc E showed a more fluctuating trend, with three remarkable drops in May, August and October, each followed by partial recovery. In particular, the October drop culminated in the lowest negative peak recorded on all classes (mean BCI of SLc E in October: 0.0299, SE = 0.0023; Figure 4D).

On average, during the sampling period, individuals of SLc $\mathrm{B}, \mathrm{C}$ and $\mathrm{D}$ were able to recover up to $90 \%$ or more of the mean $\mathrm{BCI}$ value observed on the first month of sampling, April (BCI in November was $97.6 \%, 92.6 \%$ and $90.2 \%$ of BCI observed in April for SLc B, C and D, respectively; Figure 4). The mean BCI value recorded in November on larger individuals (SLc E) was $87.2 \%$ of the mean BCI observed in April for the same class.

The number of captures per SLc showed considerable monthly variation (Figure 4). The number of individuals of SLc B remained low till July, then a positive trend began, with a remarkable peak in September followed by a steep drop in October (Figure 4A). Individuals of SLc C and D showed a more fluctuating trend, with a negative peak in June followed by an inversion of trend and a positive peak in August, and then another drop in autumn followed by a recovery. The number of individuals of SLc E remained low all through the sampling period, with mild fluctuations (Figure $4 \mathrm{D}$ ).

\section{DISCUSSION}

\section{Population structure}

In the Mediterranean Sea, the SL of C. chromis is known to range on average from a minimum of $30 \mathrm{~mm}$ in the eastcentral Adriatic to a maximum of $107 \mathrm{~mm}$ in Corsican waters (recalculated from original data, Table 3). Our population from the Tyrrhenian Sea ranged from 28 to $87 \mathrm{~mm}$,
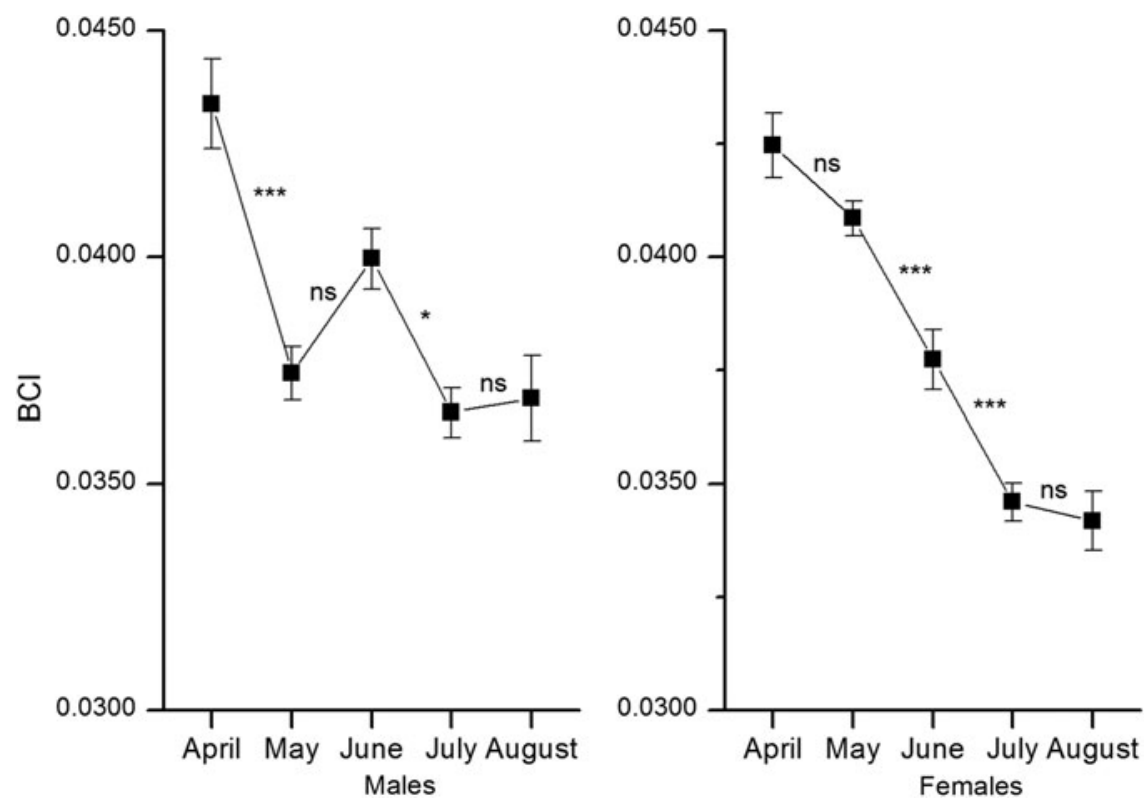

Fig. 3. The body condition index (BCI) monthly trend in Chromis chromis by sex. Black box, mean; whiskers, standard error. 

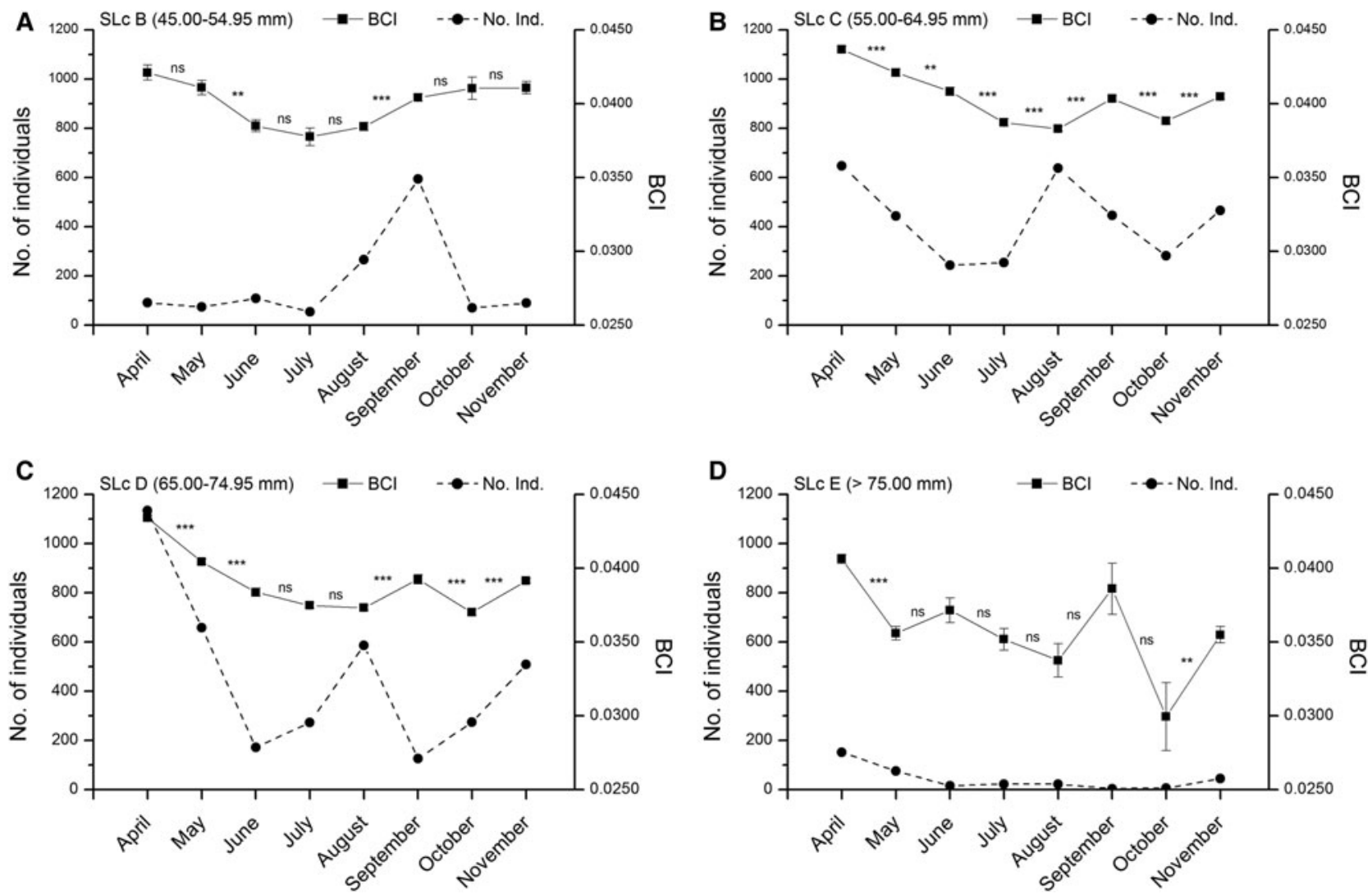

Fig. 4. Monthly captures (straight line) and body condition index (BCI) (dashed line) for standard length-classes: (A) SLc B (45-54.9 mm); (B) SLcC (55$64.9 \mathrm{~mm}$ ); (C) SLcD (65-74.9 mm); (D) SLcE ( $\geq 75 \mathrm{~mm}$ ). Black box, mean; whiskers, standard error.

which fits well within known values. While the minimum length observed in our population was close to the value reported for the Adriatic Sea, the maximum length was closer to values known for the Channel of Sicily (Table 3).

The maximum age recorded in this study was $7.5 \mathrm{yr}$, which highlights a lower maximum age than previously observed in the Adriatic Sea (9 yr (Dulčić \& Kraljević, 1995); Table 3), but similar to that estimated by modelling a Corsican population
(Pinnegar et al., 2007; Table 3). As expected for a population characterized by younger-aged, smaller individuals, the growth rate coefficient we observed in the Tyrrhenian Sea indicates an intermediate growth rate, while the Adriatic and the Corsican populations, characterized by comparatively larger individuals, were described by slower growth rates (Table 3). Fish growth depends on the energy resources allocated to somatic growth and among the main factors is the

Table 3. Summary of allometric and morphometric values observed in Chromis chromis in the Mediterranean Sea. SL, standard length;^ recalculated from total length; ^ recalculated from fork length; * from length-classes, not the actual minimum and maximum values; ${ }^{* *}$ not sampled by fishing; ${ }^{*}$ depending on model used to estimate the age.

\begin{tabular}{|c|c|c|c|c|c|c|}
\hline Area & $\begin{array}{l}\text { Allometric } \\
\text { coefficient } \\
b\end{array}$ & $\begin{array}{l}\text { Growth } \\
\text { coefficient } \\
k\left(\mathrm{y}^{-1}\right)\end{array}$ & $\begin{array}{l}\text { Maximum age } \\
(y)\end{array}$ & SL (range, mm) & $\begin{array}{l}\text { Weight } \\
\text { (range, g) }\end{array}$ & Reference \\
\hline \multicolumn{7}{|l|}{ Northern } \\
\hline Adriatic Sea & 2.64 & & & $38-104^{\wedge} *$ & & Dulčić et al. 1994 \\
\hline \multicolumn{7}{|l|}{ Eastern central } \\
\hline Adriatic Sea & 3.07 & & & $38-104^{\wedge} *$ & & Dulcic et al. 1994 \\
\hline \multicolumn{7}{|l|}{ Eastern central } \\
\hline Adriatic Sea & 3.1 & 0.26 & 9 & $30-101^{\wedge}$ & $3.24-40.21$ & Dulčić \& Kraljević 1995 \\
\hline Corsica & 3.05 & $0.46-0.49$ & $5.67-7.15^{\#}$ & $8-107^{\wedge * *}$ & $0.02-42.15$ & Pinnegar et al. 2007 \\
\hline Tyrrhenian Sea & 2.98 & 0.57 & 7.5 & $28-87$ & $0.7-25.8$ & this study \\
\hline Sicily Channel & 2.95 & & & $46-90 \hat{~}$ & $3.0-27.0$ & Duka \& Shevchenko $1980^{\S}$ \\
\hline Aegean Sea & 2.46 & & & $39-95^{\wedge}$ & & Petrakis \& Stergiou 1995 \\
\hline Aegean Sea & 2.6 & & & $61-80$ & $8-18$ & $\begin{array}{l}\text { Kapiris \& Klaoudatos } \\
2011\end{array}$ \\
\hline Black Sea & 2.87 & & & $53-75^{\wedge}$ & $6.0-17.7$ & Duka \& Shevchenko $1980^{\S}$ \\
\hline
\end{tabular}

${ }^{\S}$ Cited in Dulčić \& Kraljević (1995). 
fish feeding regime (Holm et al., 1990; Russell et al., 1996; Mōllmann et al., 2005). However, non-interactive factors such as temperature and light also play an important role (Pauly, 1980; Boeuf \& Le Bail, 1999). Indeed, metabolic rate in ectothermic organisms is usually higher at increasing temperatures (Clarke \& Johnston, 1999), which affects the growth rate (Houde, 1989; Mooij et al., 1994). For example, it has been proposed by Copp et al. (2004) that the latitudinal gradient of growth patterns in the pumpkinseed sunfish Lepomis gibbosus, an omnivorous nest guarding fish inhabiting freshwaters, may be masked by local factors such as predator pressure and competition (Copp et al., 2004).

Relationships between length and weight of Mediterranean C. chromis have been described by several authors (Table 3), and all possible values (i.e. describing isometric, as well as positive or negative allometric relationships) have been reported. The allometric coefficient $b$ describes fish shape, with negative values corresponding to thinner bodies and positive values to thicker bodies. Values close to those describing perfect isometric relationships $(b=3$, see Gould, 1966) have been found in populations from the Channel of Sicily and from Corsica, as well as in our samples from the Tyrrhenian Sea (Table 3). The length of our sampling period was eight months and started before the reproductive period. Although the overall length - weight relationship was described by an isometric coefficient (2.98), the value observed during the reproductive period was negative (e.g. 2.84 in July), while the one observed before reproduction was fully isometric (e.g. 2.99 in the month of April). This suggests that the overall isometric relationship was the result of a seasonal balance. Nevertheless, both negative and positive values during the reproductive season have been reported for the Adriatic Sea (Dulčić et al., 1994; Dulčić \& Kraljević, 1995; see Table 3). Observed differences could be due to seasonal changes in population dynamics, and could be influenced by objective (quantity or quality of the locally available feeding resources, predation pressure, genetic factors) and subjective factors (length and timing of sampling periods).

The existence of differences among local populations (Adriatic vs Tyrrhenian, etc.), as shown by parameters such as growth and body condition coefficients, suggests that population dynamics could evolve according to oceanographic gradients both at the landscape (e.g. latitudinal or longitudinal) and at the small spatial scale, fulfilling a prerequisite for the identification of $C$. chromis as a promising bioindicator. Other points in favour of the use of $C$. chromis as a bioindicator are the species' widespread abundance and distribution, coupled with its sedentary habits (Guidetti, 2000), as well as with its ability to adapt to local environmental variability (Bracciali et al., 2012).

It is worth noting here that in our population the mean SL of mature males was significantly larger than that of females (SL: $66.5 \mathrm{~mm}$ vs $62.3 \mathrm{~mm}$, respectively). A previous study carried out in the central Adriatic did not find any difference in length (SL: $73.9 \mathrm{~m}$ vs $74.0 \mathrm{~mm}$; Dulčić, 2005), as well as in other morphometric characteristics. In contrast, a limited data set from the Aegean Sea showed greater variation in females than in males, both as concerns length and body mass (TL: $81-106 \mathrm{~mm}$ vs $89-99 \mathrm{~mm}$ and weight $8-18 \mathrm{~g}$ vs $12-15 \mathrm{~g}$ (Kapiris \& Klaoudatos, 2011)). It would seem, therefore, that different C. chromis populations show different sexrelated morphometrics. If these were confirmed, it would be worth investigating the factors shaping such morphometric relationships (i.e. genetic and/or environmental factors).

\section{Seasonal variation}

In the Mediterranean Sea, the reproductive season of $C$. chromis has been reported to extend from June to September (Abel, 1961; Grubišić, 1982, cited in Dulčić \& Kraljević, 1995; Picciulin et al., 2004; Pinnegar et al., 2007), or even as starting in May in some areas of the Adriatic (Dulčić \& Kraljević, 1995). In laboratory conditions and at constant temperatures of $24-26^{\circ} \mathrm{C}$, reproduction has been observed from July to September (Contini \& Donato, 1973).

In our study, BCI values and the number of individuals captured while feeding in the water column were used to estimate the length of the reproductive period. We used BCI values to describe what happened in the period before sampling. A low BCI, for example, would be expected in July, after the June spawning.

According to trends in $\mathrm{BCI}$ and in the number of catches, it appears that the reproductive period started in May and went on until September. Most interestingly, a close look at the separate trends observed in the four length classes (Figure 4) points to a strong size-dependent effect. Individuals with a SL ranging from 45 to $54 \mathrm{~mm}$ (SLc B) were characterized by a single and continuous reproductive season lasting from May to July. Larger specimens ranging from 55 to $74 \mathrm{~mm}$ in SL (categories SLc C and D), which constituted the bulk of our sample, showed instead a bimodal trend, with two negative peaks of BCI in August and October. This is likely to indicate the occurrence of two spawning periods, separated by a recovery in September, possibly linked to larger food availability in August (Siokou-Frangou, 1996). This trend matches well with the number of individuals not engaged in reproductive activities and consequently feeding in the water column, which showed a positive peak in the month of August. Overall, the lowest BCI negative peak was recorded in October for the largest individuals (SLc E). This category underwent a more strongly fluctuating trend, with three remarkable drops, each followed by partial recovery.

As SL was age-dependent, the higher allocation of resources of larger and consequently older damselfishes is in line with the classical life-history models predicting that reproductive investment should increase with age, peaking in an act of terminal investment when there are no further opportunities for reproduction (Williams, 1966).

In multiple-spawning fish, the last spawning cycle is known to cause the depletion of the energetic reserves allocated for reproduction (Kooijman, 2010; Sarà et al., 2014), so that larger individuals are unable to recover their original BCI values before the end of the reproductive season (i.e. BCI April vs November, post-hoc pairwise comparison test, $P$ values: SLc $\mathrm{C}<0.001$; SLc $\mathrm{D}<0.001 ;$ SLc $\mathrm{E}=0.005$, Figure $4 \mathrm{~B}-\mathrm{D}$ ), in contrast to the smaller ones (i.e. SLc B, April vs September, post-hoc pairwise comparison test, $P=$ 1.00o). These findings suggest that, in spite of their high investment at the beginning of the reproductive season, our larger specimens were able to regain the metabolic energy necessary to afford further spawning, thereby probably extending their reproductive season until September. In short, the larger the size of the specimen, the better its status and the longer its reproductive season. This result might be better described by state-dependent life-history 
theory, which assumes that reproductive investment decisions depend on body condition, which may change as an individual grows older (McNamara \& Houston, 1996).

Differences in habitat use between sexes have been reported for the pre-reproductive period (Aburto-Oropeza et al., 2000), with Pinnegar et al. (2007) noting that, during the day, $C$. chromis males were comparatively more numerous than females on Posidonia seagrass. In our case, the sex-ratio of individuals captured in the month of April (e.g. before the reproductive season), was slightly in favour of males (M:F 1:0.78, Table 1), although the ratio was not significantly different from parity. The proportion of males in the water column decreased from May, meaning that, during the reproductive period, shoals were mainly composed of females. This reflects the damselfish reproductive behaviour, according to which males migrate to the bottom (Verginella et al., 1999; Gladstone, 2007a) and remain close to their nest for about 10 days, while females go to the sea bottom only at the time of oviposition (Picciulin et al., 2004). Therefore the fluctuations in sex-ratio that we observed fits well the multiplespawning behaviour known for the species (Verginella et al., 2000).

From a metabolic perspective, the general decrease in BCI that we observed from April to August in both sexes suggests that a greater energy demand was required during gonadic development and reproduction (Figure 3). Indeed, while females had to face costs for eggs production (Armstrong \& Witthames, 2012; Bapary et al., 2012), males had to sustain those related to territoriality and parental care (Gladstone, 2007a). Although in both sexes BCI showed higher values before the reproductive season and lower values during the reproductive season, this decrease followed different patterns. In males, a strong decrease was observed from April to May, probably corresponding to the time of their first seasonal colonization of the bottom (Boddeke, 1963; Charnov et al., 1976; Gladstone, 2007a), followed by a partial recovery in June (Figure 3). In contrast, female BCI gradually decreased in spite of the possibility of having access to zooplankton by remaining in the water column, thus suggesting an additive effect of multiple ovipositions, not sufficiently counterbalanced by the energy acquired by feeding in the water column. Indeed, even if before the reproductive period the BCIs of the two sexes were close, at the end of the sampling season it was lower in females than in males (0.0280 vs 0.0320 , Figure 3 ). These findings suggest that overall seasonal energetic investment in reproduction was higher in females than in males. It is also possible that physiological and/or behavioural differences between sexes allowed males to recover between the consecutive spawning cycles and to end the reproductive season with overall greater energetic reserves. Further studies focused on the different management of the energetic budget in C. chromis males and females could provide useful insights for supporting classical or statedependent life-history models.

\section{CONCLUDING REMARKS}

Even though drivers are probably different between the sexes, C. chromis also shows different seasonal dynamics depending on individual size. Females might adjust their reproductive period according to mechanisms of internal regulation, such as trade-off energy allocation between body maintenance and gonadic maturation (Kooijman, 2010), while males might be mainly driven by external stimuli, such as mating opportunities (Picciulin et al., 2004; Gladstone, 2007a). However, individuals carry on their life history activities primarily as a function of their energetic reserves (Kooijman, 2010), as well as according to social organization and hierarchy (Aburto-Oropeza et al., 2000) and even individual cognition and learning processes (van Deurs et al., 2011). We can say, therefore, that any observed shift in expected age/size class composition and/or BCI occurring on a local scale will be a consequence of often cryptic variations in ecological parameters such as food availability or perhaps water temperature. To implement fully adequate conservation activities, any such change should be carefully monitored, evaluated and taken into account.

\section{ACKNDWLEDGEMENTS}

We wish to thank Capitaneria di Porto di Palermo; Pietro Rizzo and Fabio Fiorentino (IAMC-CNR, Italy) for their help in otolith analysis, Gaspare Guzzo and Claudia Cavallaro (University of Palermo, Italy) for their help in laboratory and fieldwork and Emilio Balletto (University of Torino, Italy) for manuscript revision.

\section{FINANCIAL SUPPDRT}

Funds were provided by DINAUTIS project by the Italian Ministry for the Environment.

\section{REFERENCES}

Abel E.F. (1961) Freiwasserstudien über das Fortpflanzungsverhalten des Mönchsfisches Chromis chromis, einem Vertreter der Pomacentriden im Mittelmeer. Zeitschrift für Tierpsychologie 18, 441-449.

Aburto-Oropeza O., Sala E. and Sánchez-Ortiz C. (2000) Feeding behavior, habitat use, and abundance of the angelfish Holacanthus passer (Pomacanthidae) in the southern Sea of Cortés. Environmental Biology of Fishes 57, 435-442.

Allen G.R. (1991) Damselfishes of the world. Melle: Mergus, 271 pp.

Andersson M. (1994) Sexual selection. Princeton, NJ: Princeton University Press, $624 \mathrm{pp}$

Armstrong M.J. and Witthames P.R. (2012) Developments in understanding of fecundity of fish stocks in relation to egg production methods for estimating spawning stock biomass. Fisheries Research $117-118,35-47$.

Bacher K., Gordoa A. and Sagué O. (2012) Spatial and temporal extension of wild fish aggregation at Sparus aurata and Thunnus thynnus farms in the north-western Mediterranean. Aquaculture Environment Interactions 2, 239-252.

Bapary M.A.J., Amin M.D.N. and Takemura A. (2012) Food availability as a possible determinant for initiation and termination of reproductive activity in the tropical damselfish Chrysiptera cyanea. Marine Biology Research 8, 154-162.

Blanckenhorn W.U. (2005) Behavioral causes and consequeces of sexual size dimorphism. Ethology 111, 977-1016.

Boddeke R. (1963) Size and feeding of different types of fishes. Nature $197,714-715$. 
Boeuf G. and Le Bail P.-Y. (1999) Does light have an influence on fish growth? Aquaculture 177, 129-152.

Bracciali C., Campobello D., Giacoma C. and Sarà G. (2012) Effects of nautical traffic and noise on foraging patterns of Mediterranean damselfish (Chromis chromis). Plos One 7, e40582. DOI: 10.1371/ journal.pone.0040582.

Charnov E.L., Orians G.H. and Hyatt K. (1976) Ecological implications of resources depression. American Naturalist 110, 247-259.

Clarke A. and Johnston N.M. (1999) Scaling of metabolic rate with body mass and temperature in teleost fish. Journal of Animal Ecology 68, 893-905.

Contini A. and Donato A. (1973) Sul ciclo biologico riproduttivo del Teleosteo Chromis chromis L. Memorie di Biologia Marina e di Oceanografia 3, 173-184.

Copp G.H., Fox M.G., Przybylski M., Godinho F.N. and Vila-Gispert A. (2004) Life-time growth patterns of pumpkinseed Lepomis gibbosus introduced to Europe, relative to native North American populations. Folia Zoologia 53, 237-254.

Domínguez-Petit R., Saborido-Rey F. and Madina I. (2010) Changes of proximate composition, energy storage and condition of European hake (Merluccius merluccius, L. 1758) through the spawning season. Fisheries Research 104, 73-82.

Donelson J.M., Munday P.L., McCormik M.I., Pankhurst N.W. and Pankhurst P.M. (2010) Effects of elevated water temperature and food availability on the reproductive performance of a coral reef fish. Marine Ecology Progress Series 401, 233-243.

Dulčić J. (2005) Biometric properties of damselfish, Chromis chromis (Osteichthyes: Pomacentridae) from the middle Adriatic. Acta Adriatica 46, 91-98.

Dulčić J. and Kraljević M. (1995) Age, growth and mortality of damselfish (Chromis chromis L.) in the eastern Adriatic. Fisheries Research 22, 255-264.

Dulčić J., Kraljević M. and Cetinić P. (1994) Length - weight relationship in damselfish (Chromis chromis L.) in the central Adriatic. Acta Ichthyologica et Piscatoria 2, 141-146.

Endler J.A. (1986) Natural selection in the wild. Princeton, NJ: Princeton University Press, $336 \mathrm{pp}$.

Fasola M., Canova L., Foschi F., Novelli O. and Bressan M. (1996) Resource use by a Mediterranean rocky slope fish assemblage. P.S.Z.N. Marine Ecology 18, 51-66.

Fero K. and Moore P.A. (2008) Social spacing of crayfish in natural habitats: what role does dominance play? Behavioral Ecology and Sociobiology 62, 1119-1125.

Fischer W., Bauchot M.-L. and Schneider M. (1987) Fiches FAO d'identification des espèces pour les besoins de la pêche. Méditerranée et mer Noire. Zone de pêche 37. Volume II. Vertébrés. Publication préparée par la FAO, résultat d'un accord entre la FAO et la Commission des Communautés Européennes (Projet GCP/INT/422/EEC) financée conjointement par ces deux organisations. Rome, FAO, Volume 2, pp. $761-1530$.

Froese R. and Pauly D. (2013) FishBase. Available at: www.fishbase.org (accessed 25 March 2014).

Gladstone W. (2007a) Temporal patterns of spawning and hatching in a spawning aggregation of the temperate reef fish Chromis hypsilepis (Pomacentridae). Marine Biology 151, 1143-1152.

Gladstone W. (2007b) Selection of a spawning aggregation site by Chromis hypsilepis (Pisces: Pomacentridae): habitat structure, transport potential, and food availability. Marine Ecology Progress Series $351,235-247$.
Gonçalves J.M.S., Stergiou K.I., Hernando J.A., Puente E., Moutopoulos D.K., Arregi L., Soriguer M.C., Vilas C., Coelho R. and Erzini K. (2007) Discards from experimental trammel nets in southern European small-scale fisheries. Fisheries Research 88, 5-14.

Gould S.J. (1966) Allometry and size in ontogeny and phylogeny. Biological Reviews 42, 587-640.

Gross M.R. (1996) Alternative reproductive strategies and tactics: diversity within the sexes. Trends in Ecology and Evolution 11, 92-98.

Guidetti P. (2000) Differences among fish assemblages associated with nearshore Posidonia oceanica seagrass beds, rocky-algal reefs and unvegetated sand habitats in the Adriatic Sea. Estuarine, Coastal and Shelf Science 50, 515-529.

Guidetti P. and Sala E. (2007) Community-wide effects of marine reserves in the Mediterranean Sea. Marine Ecology Progress Series $335,43-56$.

Hobbs J.-P.A. and Munday P.L. (2004) Intraspecific competition controls spatial distribution and social organisation of the coral-dwelling goby Gobiodon histrio. Marine Ecology Progress Series 278, 253-259.

Hoelzer G.A. (1990) Male-male competition and female choice in the Cortez damselfish, Stegastes rectifraenum. Animal Behaviour 40, 339-349.

Holm J.C., Refstie T. and Bø S. (1990) The effect of fish density and feeding regime on individual growth rate and mortality in rainbow trout (Oncorhynchus mykiss). Aquaculture 89, 225-232.

Houde E.D. (1989) Comparative growth, mortality, and energetic of marine fish larvae: temperature and implied latitudinal effects. Fishery Bulletin 87, 471-495.

Jones C.G., Lawton J.H. and Shachak M. (1994) Organisms as ecosystem engineers. Oikos 69, 373-386.

Kapiris K. and Klaoudatos D. (2011) Length -weight relationship for 21 fish species caught in the Argolikos Gulf (central Aegean Sea, eastern Mediterranean). Turkish Journal of Zoology 35, 717-723.

Kooijman S.A.L.M. (2010) Dynamic Energy Budget theory for metabolic organisation. 3rd edition. Cambridge: Cambridge University Press, $72 \mathrm{pp}$.

Linton D.M. and Warner G.F. (2003) Biological indicators in the Caribbean coastal zone and their role in integrated coastal management. Ocean \& Coastal Management 46, 261-276.

McNamara J.M. and Houston A.I. (1996) State-dependent life histories. Nature 380, 215-221.

Mōllmann C., Kornilovs G., Fetter M. and Kōster F.W. (2005) Climate, zooplankton, and pelagic fish growth in the central Baltic Sea. ICES Journal of Marine Science 62, 1270-1280.

Mooij W.M., Lammens E.H.R.R. and Van Densen W.L.T. (1994) Growth rate of $o+$ fish in relation to temperature, body size, and food in shallow eutrophic lake Tjeukemeer. Canadian Journal of Fisheries and Aquatic Sciences 51, 516-526.

Nash R.D.M., Valencia A.H. and Geffen A.J. (2006) The origin of Fulton's condition factor-setting the record straight. Fisheries 31, $236-238$.

Pankhurst N.W. (1995) Hormones and reproductive behavior in male damselfish. Bulletin of Marine Science 57, 569-581.

Pauly D. (1980) On the interrelationship between natural mortality, growth parameters, and mean environmental temperature in 175 fish stocks. Journal $d u$ Conseil Permanent International pour l'Exploration de la Mer 39, 175-192.

Pecquerie L., Petitgas P. and Kooijman S.A.L.M. (2009) Modelling fish growth and reproduction in the context of the Dynamic Energy Budget 
theory to predict environmental impact on anchovy spawning duration. Journal of Sea Research 62, 93-105.

Petrakis G. and Stergiou K.I. (1995) Weight-length relationship for 33 species in Greek waters. Fisheries Research 21, 465-469.

Picciulin M., Verginella L., Spoto M. and Ferrero E.A. (2004) Colonial nesting and the importance of the body size in male parasitic reproduction of the Mediterranean damselfish Chromis chromis (Pisces: Pomacentridae). Environmental Biology of Fishes 70, 23-30.

Picciulin M., Sebastianutto L., Codarin A., Farina A. and Ferrero E.A. (2010) In situ behavioural responses to boat noise exposure of Gobius cruentatus (Gmelin, 1789; fam. Gobiidae) and Chromis chromis (Linnaeus, 1758; fam. Pomacentride) living in a Marine Protected Area. Journal of Experimental Marine Biology and Ecology 386, 125132

Pinnegar J.K. and Polunin N.V.C. (2006) Planktivorous damselfish support significant nitrogen and phosphorus fluxes to Mediterranean reefs. Marine Biology 148, 1089-1099.

Pinnegar J.K., Polunin N.V.C., Videler J.J. and de Wiljes J.J. (2007) Daily carbon, nitrogen and phosphorus budgets for the Mediterranean planktivorous damselfish Chromis chromis. Journal of Experimental Marine Biology and Ecology 352, 378-391.

R-Development Core Team (2013) R: a language and environment for statistical computing. Vienna: $\mathrm{R}$ Foundation for Statistical Computing, available at: http://www.R-project.org/ (accessed 25 March 2014).

Russell N.R., Fish J.D. and Wootton R.J. (1996) Feeding and growth of juvenile sea bass: the effect of ration and temperature on growth rate and efficiency. Journal of Fish Biology 49, 206-220.

Sarà G., Rinaldi A. and Montalto V. (2014) Thinking beyond organism energy use: a trait based bioenergetic mechanistic approach for predictions of life history traits in marine organisms. Marine Ecology. doi: $10.1111 /$ maec.12106.
Siokou-Frangou I. (1996) Zooplankton annual cycle in a Mediterranean coastal area. Journal of Plankton Research 18, 203-223.

Taborsky M. (1998) Sperm competition in fish: 'Bourgeois' males and parasitic spawning. Trends in Ecology and Evolution 13, 222-227.

Taborsky M. (2001) The evolution of parasitic and cooperative reproductive behaviors in fishes. Journal of Heredity 92, 100-110.

Tsagarakis K., Vassilopoulou V., Kallianiotis A. and Machias A. (2012) Discards of the purse seine fishery targeting small pelagic fish in the eastern Mediterranean Sea. Scientia Marina 76, 561- 572.

van Deurs M., Behrens J.W., Warnar T. and Steffensen J.F. (2011) Primary versus secondary drivers of foraging activity in sandeel schools (Ammodytes tobianus). Marine Biology 158, 1781-1789.

Verginella L., Spoto M., Ciriaci S. and Ferrero E.A. (1999) Reproductive ethogram of the Mediterranean damselfish Chromis chromis L. (Pisces: Pomacentridae) territorial male. Bollettino della Società Adriatica 78 , 437-454.

Verginella L., Spoto M. and Ferrero E.A. (2000) Spawning behaviour sequence analysis of the Mediterranean damselfish Chromis chromis (Pomacentridae) in the field. Zeitschrift für Fischkunde 5, 3-10.

Webster M.S. and Hixon M.A. (2000) Mechanisms and individual consequences of intraspecific competition in a coral-reef fish. Marine Ecology Progress Series 196, 187-194

and

Williams G.C. (1996) Adaptation and natural selection. Princeton NJ: Princeton University Press, $320 \mathrm{pp}$

\section{Correspondence should be addressed to:} C. Bracciali Department of Life Sciences and Systems Biology, University of Torino, Via Accademia Albertina 13, 10123 Torino, Italy email: claudiabracciali@gmail.com 